\title{
Effect of Emotional Intelligence Training Intervention on Nursing Students' Emotional Intelligence and Empathy Level
}

\author{
Neama Mohamed Fouad Kamel, Assistant Professor \\ Psychiatric Nursing and Mental Health, Faculty of Nursing, Alexandria University
}

\author{
Aleya Mohamed Gamal Al Dean, Assistant Professor \\ Psychiatric Nursing and Mental Health, Faculty of Nursing, Alexandria University \\ Ola Ahmed Rashad Lachine, Assistant Professor \\ Psychiatric Nursing and Mental Health, Faculty of Nursing, Alexandria University \\ Amal Awad Abd El-Nabi Moussa, Lecturer \\ Psychiatric Nursing and Mental Health, Faculty of Nursing, Damanhour University
}

\begin{abstract}
Emotional intelligence (EI) and its significance to nursing have been increasingly emphasized throughout the last few years. Emotional intelligence is composed of a deposit of interrelated skills involving a capability to appraise one's own emotions, and those of others, utilization \&regulation of own emotions, social skills, and optimism. Empathy also has been described as a necessary element of the nurse-patient relationship and its link to emotional intelligence has been reported. Accordingly, EI training skills can be incorporated into educational training intervention to promote these skills. Objective: Investigate the effect of emotional intelligence educational training intervention on levels of emotional intelligence and empathy among nursing students of Damanhour University. Setting: Fourth year nursing students, Faculty of Nursing, Damanhour University. Subjects: Twenty nine students enrolled in Psychiatric and Mental Health Nursing course, and a matched group of twenty nine students enrolled in the Community Health Nursing course. Tools: Three tools were used for data collection 1) Socio-demographic and academic data tool 2) Jefferson Scale of Empathy (JSPE) 3) Emotional Intelligence Scale. Results: The present study findings showed that empathy\& emotional intelligence improved over a four weeks period after introducing training intervention for the study subjects. Conclusion: Emotional Intelligence training has can improve students' empathy, appraisal of students own emotion and regulation and utilization of emotions. Recommendations: Emotional Intelligence courses should be held in curriculum of nursing for students and nursing staff to improve their empathic talents and emotional intelligence.
\end{abstract}

Keywords: Emotional intelligence; Empathy; Nursing students; Training.

\section{Introduction}

Undergraduate nursing students are involved in a highly-stressful environment generated by numerous variables which include extensive workloads for long period of time, and having to communicate with different personnel, extending from patients to healthcare groups and their colleagues. Psychological distresses among nursing students are well documented ${ }^{(1)}$. Studies have shown that high levels of Emotional Intelligence (EI) are linked to diminished tension, stress and effective coping pattern amongst students and other healthcare workers. Emotional intelligence furthermore has been reported to contribute positively to communication, relationships skills, empathy, and prevention of burnout. These competencies could prevent emotional confusion, and as a result, emotional breakdown and help individuals to function effectively in stressful environments ${ }^{(2,3)}$.

Emotional intelligence and its
significance to nursing have been
increasingly emphasized throughout the last
few years. Fujino (2015) discussed the


helpful roles of emotions in patients care and how emotional intelligence permits nurses to be more confident in their performance. Likewise, Esmaeili et al. (2015) investigated the importance of emotional intelligence in establishing effective relationships and how it enables nurses to control stress and burnout more efficiently. Other researchers have suggested that emotional intelligence is associated with everything from decisionmaking to academic accomplishment. Those who have a high level of EI find it easier to interact and connect with others, had greater academic and professional accomplishment and were perceived by their peers to be more sociable and have better interpersonal relationships. Those with higher EI are also appearing to be more likely to regulate, understand and manage emotions better both in themselves and in others ${ }^{(4-8)}$.

The term emotional intelligence (EI) was first expressed by Salovey (1990's) who reported that EI was of great value for human interactions and relationships. Various definitions of emotional intelligence have been provided, but in short, it is the ability to recognize, distinguish, and use emotions efficiently. Emotional intelligence is composed of a set of interrelated skills involving the capability to recognize personal emotions and those of others, and the ability to use and manage emotions $^{(9,10)}$. According to Ugoani (2015), there are five main elements to emotional intelligence: Self-awareness, Selfregulation, Motivation, Social skills and Empathy. Researchers have shown that empathy is a key component of emotional intelligence. Empathy has been recognized as being at the center of the therapeutic practice. Furthermore, emotional intelligence has both interpersonal and intrapersonal aspect as expressed in the multiple intelligence theory. Intrapersonal intelligence is the inner intelligence one uses to know oneself which is significant for self-knowledge, self-regulation and selfinspiration. Interpersonal intelligence is the external intelligence one uses to know and control relationships with other people which is attributed to empathy ${ }^{(5,11)}$.

Empathy has been described as a necessary element of nurse-patient relationship and its link to emotional intelligence has been reported. Empathy is the competence to recognize and exchange feelings with others. It is more than "active listening" to the patient and display attentive behaviors. In practice empathy has been connected with clients' happiness, satisfaction, and health improvement. Nurses are the most trust professional person in health care, and, as such, patients expected to have nurses who are concerned about them and display empathetic and caring attitude. Without empathy, nurses will fail to recognize and react to the patients' concerns. To promote effective nurse-patient relationships and thus promote the patients' physical and emotional wellbeing, the nurse must be able to respond to clients empathically, competently, and intelligently ${ }^{(12-14),}$

Emotional intelligence and empathy appeared to be associated. For the nursepatient relationship, emotional intelligence, and empathy are major elements in the management plan of any health problems. Empathetic nurses are also more likely to create client's trust, satisfaction, and compliance, and to achieve better outcomes in clinical performance. In addition, emotional intelligence increases nurse's ability to take accurate decisions, leading to greater job satisfaction and well-being, and better relationship and leadership skills within their healthcare team. According to Goleman (2013), leaders with low emotional intelligence usually have low awareness and self-control of their emotions. They have less empathy for others and a weaker ability to connect and communicate to others ${ }^{(15-17)}$.

Research suggested that if health care practitioners have difficulty managing their emotions, they may become emotionally exhausted over time. Nasir (2010) explained that EI involves the capability not merely to recognize and understand one's 
own and other's feelings, but it also incorporates the skill of how to control feelings. Therefore undergraduate nursing students with elevated EI are more likely to have self-care talent, that protect them from becoming victims of the unavoidable stress associated with the nurses work ${ }^{(3,4,18)}$.

Studies suggested that EI can be enhanced through education and training. Moreover, investigating the correlation between EI and empathy may help those concerned in nursing education. Emotional intelligence training moreover help undergraduate students to expand their selfawareness and emotional control direction, which allow better understanding of others viewpoint, stress reduction and empathy. Teaching emotional intelligence to nursing students assist them achieve insight into what the client is experiencing, what the illness event means to the patient and how it influences the patient's life ${ }^{(3,5,19)}$.

Whereas a few authors recognize that emotional intelligence is not an enduring lifetime character but can be enhanced under correct circumstances, others proposed that emotional intelligence is a permanent quality that, if present, will always exist. Conversely, other authors suggest that even if the person has restricted emotional intelligence, it can be improved with proper preparation. Consequently because most people are hired for their qualifications and expertise, applicants for nursing may be excluded if their inborn aptitude for emotional intelligence is limited.

As emotional intelligence can be enhanced, nursing students need to learn emotional skills to develop their empathy, outward expression and control of their emotions in order to ensure high quality nursing care, team work and virtuous relation with their colleagues in their future practices, as well as for their own wellbeing. The advantages of emotional intelligence education for undergraduate students expand beyond stress reduction and include higher attention \& concentration, quicker information process which facilitates greater academic performance, better self-reflexivity, and increased student commitment. Although the importance of EI in nursing, nurses feel insufficiently prepared for the social, interpersonal and emotional demands of their roles. This indicates that nurses are not well qualified to adjust to the working demand. Globally, data regarding the effect of EI training on the empathy of nursing undergraduates are limited. This study aims to examine the effect of emotional intelligence training on nursing students' emotional intelligence and its association with level of empathy ${ }^{(20-24)}$.

\section{Aim of the Study}

This study aims to investigate the effects of emotional intelligence educational training intervention on levels of emotional intelligence and empathy among nursing students of Damanhour University.

\section{Research Question}

$\begin{aligned} & \text { What are the effects of emotional } \\ & \text { intelligence educational training }\end{aligned}$
intervention on levels of emotional
intelligence and empathy among nursing
students?

\section{Materials and Method}

Materials

Design: This study used a quasiexperimental research design.

Setting: The study was conducted on fourth year nursing students at the Faculty of Nursing Damanhour University.

Subjects: Twenty nine students enrolled in Psychiatric \& Mental Health Nursing course were selected randomly and assigned to be the experimental group. Full details about selection of experimental group were shown under methodology section. A matched group of 29 students was selected from those enrolled in the community course assigned to be the control group.

$\underline{\text { Tools: }}$ Three tools were used to collect the study data: 


\section{Tool I: Socio-demographic and academic data tool.}

This tool was developed by the researchers to elicit information about students' age, marital status, residency, current or previous private work, and final grade of the previous year

\section{Tool II: Jefferson Scale of Empathy (JSPE-SV)}

This scale was originally developed to measure medical students' empathy in patient-care situation. The English language version of the JSPE-SV questionnaire was used as it was preferred by the participant nursing students. It consists of 20 items self-administered questionnaire with a total score ranging from 20 to 140 . Students reported their conformity to each statement of the 20-item questionnaire on a 7-point Likert scale. High score indicates high levels of empathy. According to Fields et al. (2011) the JSPE-HPS is the only tool designed to measure empathy scores specifically in health care provider students that has been tested in this population for reliability and validity (Cronbach's alpha=0.58-0.69). Items no $1,3,7,8,11,12$, $14,18,19,20$ have reversed score. A split of the empathy score (ES) was performed to be high if the percentage score were $95 \%$ or more, moderate if the percentage scores was $75 \%$ and low if less than $55 \% \%^{(25,26,27)}$. The measurement of internal consistency (Cronbach'salpha) is 0.76.12.

\section{Tool III: Emotional Intelligence Scale}

This scale was developed by Schutte et al. (1998). It is composed of 33-items scale with a five-point Likert-type scale. The scale has six main categories: appraisal of others emotions assessed by 7 items, appraisal of own emotions assessed by 5 items, regulation of emotions assessed by 5 items, social skills assessed by 5 items, utilization of emotions assessed by 7 items, and optimism assessed by 4 items. Students read each statement and decide whether they 'strongly agree', 'agree', 'undecided', 'disagree', or 'strongly disagree' with the statement. This scale has a Cronbach alpha $(\alpha)$ of 0.90 for the internal consistency and $\alpha=0.78$ for test-retest reliability after a twoweek interval. Score ranging from 33 to 165. Emotional intelligence was considered to be high if the percent score was $75 \%$ or more and low if less than $75 \%$. Scores were reversed for negative statements (questions number 5, 28, and 33) ${ }^{(28,29)}$.

\section{Method}

\section{- Preparation of study tools:}

- The socio-demographic and clinical data tool was developed by the researchers.

- Assessment tool for data collection was examined for the content validity by a jury from 5 experts in the related field.

- A pilot study was conducted on $10 \%$ of the subjects to ascertain the clarity and applicability of the study tools and to identify the obstacles that may be faced during data collection. The results of the pilot study revealed that the tools were clear and applicable. These subjects were excluded from the actual study.

- Reliabilities of tools II \& III were done on 20 students using internal consistency Cronbach's alpha correlation. The results proved that the tools were reliable with a correlation coefficient of 65 for tool II and 83 for tool III.

\section{- Actual study:}

\section{- Phase I: Selection of participants:}

Students of the experimental group were ranked by simple randomization by picking their names up from a pool. They were ranked according to priority of pulling from the pool, i.e. the first selected student from the pool would be the starting one for data collection, and then the second would be the next one and so on until the required number of students is reached. The study group 
was selected from students enrolled in psychiatric nursing course. Control group was selected from community health nursing students (using the same simple randomization) to avoid contamination, and making sure to consider appropriate matching with study group.

- Phase II: Implementation of emotional intelligence training intervention:

Sessions of emotional intelligence training intervention were conducted for 90 minutes, every week for a period of four weeks. The content of emotional intelligence training intervention was developed by the researchers after a thorough review of the literature $(28,29)$. It includes the following systematic skills that had been taught in four sessions. Skills were taught gradually from simple and basic to more complex one. The main topics included discussion, application and assignments about the following:

- The concept of emotional intelligence and its main dimensions.

- Self-awareness.

- Social awareness.

- Application of empathy and self-control.

Students of the study group were divided into two groups, each group constituted about 14 or 15 students. In the first session, the researchers met the students in the place of psychiatric mental health nursing theoretical lecture, greeted them, allowed the students to take their seats and introduced themselves to them as well as each student to the others. The oral informed consent of the students to participate in the study was also taken. In addition, the purpose of the study was explained to the students, brief and simple explanation was provided about the training intervention and the students have been reassured that all information would be confidential and used only for the purpose of the study. The researcher then provided detailed information in relation to:

- Number of the group members, place of meeting, duration of the training.

- Frequency of meetings and length of each session.

- Clarification of the specific goals of the training intervention.

- Grounded rules of the group dynamics e.g. confidentiality and honesty.

- What to expect in the group in terms of their own roles e.g. listen attentively for each other.

- Role of each group member.

- Homework assignment that would be given at the end of each session.

In each session, the researcher started with reviewing homework assignment of previous skill and positive reinforcement was provided for students' effort. The rest of the time was consumed in the description of the session's objectives, explaining the rationale for its importance, role playing by the researcher and students to practice the skill and discussing with the students specific steps to learn this skill were also done. The educational strategies that have been used in the training intervention were brain storming, group discussion and role playing. Each session covered specific outline, specific objectives, importance of the skill to be taught, examples from real life and, the specific steps needed to learn the skill.

At the end of the training intervention a closing session was done to get the students' feedback and opinions about the training intervention. 
Data collection started from 27 March to the end of April 2018.

\section{- Phase III: Evaluation of the effectiveness of training intervention.}

Students of both group were exposed to the pre-test assessment using tools I, II and III. This consumed about 10-15 minutes. A post-test was done for the study group after conducting the training intervention through applying study tools II \&III on each student on an individual base. A post-test was also done for the control group after a matched number of days compared to the study group. As for the control group; the researcher had to wait until finishing the implementation of the training intervention on the study group. A comparison between the study and control groups was done to identify the effectiveness of the training intervention on levels of emotional intelligence as well as empathy skill among nursing students.

\section{Ethical considerations:}

An official approval was obtained from the dean of Faculty of Nursing, Damanhour University to conduct the study. Before embarking on the actual study, an oral informed consent was obtained from the students to participate in the study. Confidentiality and privacy were maintained.

\section{Statistical Analysis}

Data collected were analyzed by computer using the Statistical Package for Social Science (SPSS) software version 20.Reliability of the tools was determined by Cronbach Coefficient alpha. Data were presented by descriptive statistics in the form of frequencies and percentages for qualitative variables, and arithmetic mean, mean percent and standard deviation for quantitative variables. Pearson Correlation Coefficient was used for testing relationship between variables. Significant difference was considered if $\mathrm{p} \leq 0.05$.

\section{Results}

Table (1) shows the distribution of the students according to their socio demographic characteristics. It can be noticed that all subject in the study group were in the age group ranging from 20 to 22 year where most subjects in the control group $(94.9 \%)$ were in the same age group, and only $5.2 \%$ were 24 years or more. The table also reveals that there was no statistical significant difference between study and control groups regarding the age, marital status, place of residence, previous academic performance and current or previous work during studies. Comparison was done using Chi-Square test $\left(\chi^{2}=5.630\right.$, $0.351,0.748,3.425$ and 2.485 respectively). The absence of any statistical significant difference between the studied groups can reflect that both groups are matching.

Table (2) reveals the distribution of students according to empathy total scores pre and post intervention. Comparison was done to examine the association between study and control group's empathy total scores. No statistical significant difference was found between the two groups before starting the intervention. In the postintervention phase statistically significant difference was found between the two group $\left(\chi^{2}=16.75, P=0.000\right)$. It can be shown that there was an improvement in the total percentage score of empathy among study subject after the intervention as it was $86.2 \%$ moderate empathy \& $13.8 \%$ high empathy \& reached to $100 \%$ after the intervention whereas total percentage score of high empathy level among control group has also improved from $34.5 \%$ to $44.8 \%$. Moreover, the association between pre and post study group total empathy score was significant $\left(\chi^{2}=4.296, \mathrm{P}=0.038 *\right)$.

Table (3) illustrates the distribution of students according to their emotional intelligence. No statistical significant difference was found between the two groups before starting the intervention. In the post- intervention phase although the association between study and control emotional intelligence total score was not 
statistically significant $\left(\chi^{2}=1.96, \mathrm{P}=0.354\right)$, It can be observed that, about two thirds of studied subject in study group (65.5\%) have low emotional intelligence total scores prior to the intervention while almost all of them $(96.6 \%)$ obtained high emotional intelligence total scores post intervention. However, high emotional intelligence scores for the control group improved from $48.3 \%$ to $86.2 \%$ only.

Table (4) shows the distribution of students according to their emotional intelligence subscales scores pre and post intervention. Concerning appraisal of others emotions subscale, it can be noticed that there was an improvement among the study group in their high score percent as it was $17.2 \%$ and increased to be $51.7 \%$. In contrast appraisal of others emotions high percent score was slightly improved among control group from $27.6 \%$ to $31.0 \%$. These changes were not statistically significant among both study and control group $\left(\chi^{2}=0.892, \quad \mathrm{P}=0.344, \quad \chi^{2}=0.83, \quad \mathrm{p}=0.772\right.$ respectively). The same was found in relation to optimisms subscales, since there were no statistical significant difference among study and control group $\left(\chi^{2}=2.843\right.$, $\mathrm{P}=0.593 \quad$ and $\quad \chi^{2}=0.292, \quad \mathrm{P}=0.787$ respectively). In relation to appraisal of own emotions subscale, it can be observed that there was an improvement among the study group in their mean percent score as it was $48.3 \%$ and increased to be $96.6 \%$. These changes were statistically significant among the study group $\left(\chi^{2}=20.69, \quad \mathrm{P}=0.000 *\right)$. However, appraisal of own emotions mean percent score among control group improved from 62.1 to 65.5 only without any significant difference $\left(\chi^{2}=0.351\right.$, $\mathrm{P}=0.552$ ).

As for the utilization of emotions subscales, it can be observed that, there was an improvement among the study group in their mean percent score as it was $34.5 \%$ and increased to be $96.6 \%$. These changes proved a statistically significant difference $\left(\chi^{2}=9.087, \mathrm{P}=0.002\right)$ However, the mean percent score among the control group changed from $55.2 \%$ to $65.5 \%$ with no statistical significant difference $\left(\chi^{2}=0.648\right.$, $\mathrm{P}=0.421)$. The same was found in relation to regulations of emotions as there was a statistically significant difference among the study group after the ET intervention $\left(\chi^{2}=20.62 \mathrm{P}=0.000^{*}\right)$ while no significant difference was found among the control group $\left(\chi^{2}=0.623, \mathrm{P}=0.429\right)$.

Lastly, social skills subscale mean percent scores was improved among both study group and control group as it was $44.8 \%$ and increased to be $93.1 \%$ in the study group and improved from 44.8 to 72.4 among control group. These changes were statistically significant among both study and control group $\left(\chi^{2}=15.79, \mathrm{P}=0.000\right.$ *, $\chi^{2}=4.549, \mathrm{P}=0.033 *$ respectively).

Table (5) shows the distribution of the students according to their empathy total mean scores before and after intervention, it can be observed that, the total empathy score of the study group increased from $67.97 \pm 4.99$ to $71.45 \pm 6.85$ with a mean change of $3.48 \pm 1.86$ whereas that of the control group increased slightly from $77.45 \pm 14.76$ to $78.59 \pm 15.25$ with a mean change of $1.14 \pm 0.49$. The association between study and control empathy total mean score after intervention proved to be statistically significant. $\quad\left(\mathrm{F}^{\mathrm{b}}=3.618\right.$, $\mathrm{P}=0.001 *)$. Also, there was a statistical significant difference between empathy mean score before and after intervention among the study group $(\mathrm{t}=2.966$, $\mathrm{P}=0.006 *)$.

Table (6) illustrates the distribution of the students according to their emotional intelligence total mean scores before and after intervention. It can be noticed that, the total emotional intelligence score of the study group increased from $119.28 \pm 12.6$ to $135.07 \pm 6.52$ with a mean change of $15.79 \pm 6.08$, whereas that of the control group also increased from $120.10 \pm 7.58$ to $133.79 \pm 10.73$ with a mean change of 13.69 \pm 3.15 . Statistical differences between study and control group in relation to emotional intelligence total mean score before and after the ET intervention were found $\quad(t=7.713, \quad P=0.000 *, \quad t=-6.756$, 
$\mathrm{P}=0.000 *$ respectively). The association between study and control emotional intelligence total mean scores before and after intervention was not statistically significant $(\mathrm{F}=1.662, \mathrm{P}=1.849 \& \mathrm{~F}=1.641$, $\mathrm{P}=0.193$ respectively).

\section{Discussion}

The findings of the actual study reveal that empathy score were significantly elevated in the post phase than in the prior intervention phase among the study group, while no significant change was observed in the corresponding control group. The results of inter group comparison show statistical considerable discrepancy between the two groups in terms of empathy level. This means that, the noted variation in the empathic score among the students in the post intervention phase could be attributed to the consequences of intervention. This indicates that the introduction of $\mathrm{EI}$ intervention was successful in elevating the level of empathy among nursing students across 4 weeks of practices, as students started to be aware and oriented with their emotions and feelings.

As regards the EI total score, the results of the actual study also indicated that in the study group, the EI total mean scores increased significantly in the post-training phase compared to the pre training phase. It was also observed that, the total mean score of emotional intelligence were improved more in the study group as contrasted to the control group although no statistically significant difference were obtained between both study and control group in the post- intervention phase, which may refers to the nature of the study in the faculty which stressed on the importance of self awareness and how the nurse can identify patients emotions and how the nurses can use their emotions effectively in different areas/situations.

Review of literatures reveled that few studies have assessed the effect of emotional intelligence training program on the development of empathic skills, while several studies show that the application of the empathy training program increased the level of empathic skills. In this regard, Aktas et al. (2014) carried out a study on fifteen working midwives and showed that the mean scores of empathic communication skills significantly increased after thirty two hours of training. Kahriman et al. (2016) carried out a study on forty eight nurses and discovered that the empathic skill score considerably improved in the experimental group after empathy educational modules. Cunico Laura et al. (2012) conducted a study on one hundred three nursing students using the Emotional Empathy Balanced Scale and confirmed that the mean scores of the empathy skills in the intervention group considerably improved after a 21-hour empathy training session. A study conducted by Ozcanet al. (2012) scheduled for two hundred fifty seven medical and nursing students revealed that the degree of self-evaluation communication and empathy skills increased after ten hours of exercising empathy talents about one month period ${ }^{(30-}$ 33).

Moreover, there are limited studies that assess the effect of EI training program on students or nurses as subjects of study. In this regard, a study reported that EI training improved not only nurses' students' EI but also empathy. In a study where empathy was measured as an outcome in health care providers, levels of empathy significantly improved following an emotional intelligence intervention. Consistency with the finding of the actual study, Akbariet al. (2010) reported that a one month educational program, consisting of a 2.5hour weeks session, significantly enhanced the EI level of psychology students, other establish that an EI educational program consisting of 15 sessions (1 hour for every session) significantly improved the selfassertiveness, self-respect, problem-solving abilities and EI-related skills of Iranian high school students. Beauvais et al. (2011) found that the educational program considerably enhanced EI scores, EI skills among nursing students. Conflicting with the results of the present study, Orak (2016) 
found that two months EI training program had no effect on the EI skills of preparatory year of nursing students at Iranian university $^{(33-36)}$. In the actual study, the failure to obtain statistical significant difference between the two groups in term of the total EI mean score can be attributed to short time of the training intervention. It therefore suggests, introducing emotional intelligence training program over an extended period of time to ensure that all component of emotional intelligence is maintained.

Whereas there is obvious proof intended for the relationship between EI/empathy and enhancement of client care, there is also proof that nurses with elevated level of sympathy are at high risk of stress from emotional exhaustion. Extremely empathetic nurses may possibility be at risk of emotional fatigue and burnout and consequently they require to control and manage their emotional status. EI incorporates not only the ability to recognize and understand one's own and other's emotions, but it also involves the ability of how to manage and control emotions. Therefore the ET educational training intervention is a helpful step towards not only improving empathy skills, but also protecting the nurse form the unnecessary increase in stress and burn out ${ }^{(20,37)}$. Therefore, the curriculum of nursing sciences should include the practical training of ET not only to enhance the students' empathetic skills but also to advance their emotional intelligence in order to enhance patient care and improve the quality of psychological care, as well as to enhance nurses' ability to manage and control their emotions for their own wellbeing.

Unexpectedly, the results of the actual study also show that in the control group the total emotional intelligence also changed after the intervention. This can be explained by several factors, including short time of the introduced training intervention, inability to give the students enough time to apply their newly acquired skills and subject size that may have been inadequately large to account for significant change between the two groups.

In addition, the control group is composed students from the same college and same year therefore the variations observed in participants may occur partially as a result of students' progression through their courses, rather than due to the ET intervention itself. The students in this study were in the fourth year and they practiced communication skills exercises throughout their previous academic year at the college. They were also exposed to clinical experience where they practice social skills with patients and families under supervision and continuous assessment of faculty members of the college. Colleges of nurses are different from most of other medical and health professional colleges where communication skills and exposure to clinical environments had started later.

Consistent with the present study, Saeed et al. (2018) indicated that after a training intervention, emotional intelligence and its individual components improved not only in the intervention group but also in the control group $^{(35)}$.

The current results also contradicted those that investigated the effect of seven month extended EI training on medical students' EI skills. The students were permitted one month to implement skills acquired from the last session attended. The researcher reported that although the EI scores in the experiment group considerably increased over time, the reverse was true for the control group, i.e., the scores declined $^{(36-38)}$.

The results of this study illustrated that within the emotional intelligence subgroup, appraisal of students own emotion is significantly increased in the study group after the intervention as compared to prior the intervention. Utilization and regulation of emotion, which means control and regulation of emotions in oneself and others, such as deliberately cooling down after feeling angry or being able to alleviate the anxiety of another person, showed 
significant improvement in the intervention group as compared to the control. So, it appears that the implementation of the EI education course improved the intensity of students' appraisal of their own emotion and ability of nursing students to utilize and regulate their emotions more than the other components.

In this regard, Keshavarz et al. (2013) comments that appraisal of own emotion, which indicates self-awareness and valuable knowledge of individuals about their aptitude and potency, is the most basic branch of EI. Others comment that individuals with high EI score had good relations with their superiors and display trust and empathy. They can think clearly and creatively, can appraise their own emotions, and had self-control over their emotions. In this respect Saeed et al. (2018) commented that emotion regulation refers not only to efforts to monitor and suppress the unwanted emotional responses but also one's positive emotions states. Orak RJ et al. (2016) added that sometimes positive emotions should be down regulated as negative emotion to maintain task focus ${ }^{(36)}$.

The findings of this study are also consistent with Keshavarz et al. (2013) who found that self-awareness and emotion regulation had the strongest association. Others added that students must be reinforced to be acquainted with themselves, to realize their weaknesses and strengths, to appraise their emotional responses to different events and to gain skills of emotional control ${ }^{(22,36,39)}$.

Moreover the sub item social skills are significantly increased among nursing student in both intervention and control group after implementation of the training. These results might be attributed to factors other than the intervention training as previously mentioned, such as the college education curriculum students had received.

The results of the actual study also fail to find any significant improvement in the score of optimism and appraisal of other emotions, in the post-training phase among both groups. This result might be attributed to the length of the training course that may be not sufficient to provide needed improvement or due to inability to offer sufficient time to the students to carry out their recently acquired skills. Consistent with our results, Saeed Abbasi (2018) established that a two month EI educational course had no effect on all EI subgroup including optimism and appraisal of other emotion of first-year nursing students ${ }^{(32,38)}$.

The findings of the present study also contradict studies who concluded that optimism and appraisal of other emotion predicts emotional intelligence and that a four week educational training intervention, held on alternating weeks, significantly improved the EI total scores including the subcomponent optimism and appraisal of other emotion. Other added that optimism is an important element to predict EI and those optimist individuals are more successful in schools, have happier, healthier life, and are more concerned about their children than other ${ }^{(40,41)}$.

\section{Limitations of the study}

The limitations of this study are related to small sample size, and assessing the outcome immediately after the presentation of the ET training intervention. In addition, the control group in this study are students from the same college and same academic year therefore the variations noted among the control and experimental studied subject may have come as a result of students' progression through their courses, rather than due to the species influence of ET training. Future studies ought to consider utilizing distinctive college in comparative studies in order to identify the association of ET training and the development of emotional intelligence and empathy.

\section{Conclusion}

The outcomes of this research indicated that EI can be trained and learned, throughout an educational course so it can improve the empathic talents and emotional intelligence of students. This study also showed that, empathy was improved over a 
four week period when emotional intelligence training was introduced to the fourth year nursing students at Damanhour University.

Outcomes of this study showed that among the emotional intelligence subgroup, appraisal of students own emotion and regulation and utilization of emotions had significant improvement in the study group as compared to the corresponding group. Moreover, the sub items social skills are considerably increased among nursing student in both study and corresponding group. Consequently it seems that the completion of the EI teaching course increased the level of emotional appraisal, regulation and utilization of emotion ability of nursing students more than the other components. Moreover the sub items appraisal of other emotion and optimism need more training time in order to produce significant increase among nursing students.

\section{Recommendations}

It is recommended that future studies should consider using different college in similar studies as a control group in order to identify the relationship between ET education training intervention and the development of emotional inelegancy.

It is also recommended that further study should be done to investigate the outcome of EI training after offering sufficient time to the students to carry out their recently acquired skills.

Therefore, it is suggested that emotional intelligence courses should be held in curriculum of nursing students and for hospital nursing staff. Health care educators should also introduce emotional intelligence training intervention over an extensive episode of time to make certain that all component of emotional intelligence is maintained. It is also recommended that researchers and experts examine emotional intelligence from an academic viewpoint among the different health care sectors. 
Table (1): Distribution of students according to their socio demographic characteristics in the two groups

\begin{tabular}{|c|c|c|c|c|c|c|c|}
\hline \multirow[t]{3}{*}{ Characteristics } & \multicolumn{3}{|c|}{ Type of Group } & \multicolumn{3}{|c|}{ Total } & \multirow{3}{*}{$\begin{array}{c}\text { Test of } \\
\text { Significance } \\
\text { between study } \\
\text { \& control }\end{array}$} \\
\hline & \multicolumn{2}{|c|}{$\begin{array}{c}\text { Study } \\
(n=29)\end{array}$} & \multicolumn{2}{|c|}{$\begin{array}{c}\text { Control } \\
(n=29)\end{array}$} & \multicolumn{2}{|c|}{$(n=58)$} & \\
\hline & No & $\%$ & No & $\%$ & No & $\%$ & \\
\hline \multicolumn{8}{|l|}{ Age (years) } \\
\hline$-\quad 20-$ & 15 & 51.7 & 8 & 27.6 & 23 & 39.7 & \multirow{4}{*}{$\begin{array}{l}\chi^{2}=5.630 \\
\mathbf{P}=0.059\end{array}$} \\
\hline$-\quad 22-$ & 14 & 48.3 & 18 & 62.0 & 32 & 55.2 & \\
\hline$-\quad 24+$ & 0 & 0.0 & 3 & 10.3 & 3 & 5.2 & \\
\hline $\mathrm{X}_{ \pm} \mathrm{SD}$ & \multicolumn{2}{|c|}{$21.66 \pm 0.769$} & \multicolumn{2}{|c|}{$21.97 \pm 0.865$} & & & \\
\hline \multicolumn{8}{|l|}{ Marital status } \\
\hline - Single & 28 & 96.6 & 27 & 93.1 & 55 & 94.8 & $\chi^{2}=0.351$ \\
\hline - $\quad$ Married & 1 & 3.4 & 2 & 6.9 & 3 & 5.2 & $\mathbf{P}=0.553$ \\
\hline \multicolumn{8}{|l|}{ Place of residence } \\
\hline - $\quad$ Rural & 19 & 65.5 & 22 & 75.9 & 41 & 70.7 & $\chi^{2}=0.748$ \\
\hline - Urban & 10 & 34.5 & 7 & 24.1 & 17 & 29.3 & $\widehat{P}=0.386$ \\
\hline \multicolumn{8}{|c|}{ Previous academic performance } \\
\hline - $\quad$ Excellent & 15 & 51.7 & 14 & 48.3 & 29 & 50.0 & $\chi^{2}=3.425$ \\
\hline - Very good & 13 & 44.8 & 10 & 34.5 & 23 & 39.7 & $\mathbf{P}=0.330$ \\
\hline - Good & 1 & 3.4 & 3 & 10.3 & 4 & 6.9 & \\
\hline - Fair & 0 & 0.0 & 2 & 6.9 & 2 & 3.4 & \\
\hline \multicolumn{8}{|c|}{ Current/ previous work during education (in hospitals) } \\
\hline - Yes & 17 & 58.6 & 11 & 37.9 & 28 & 48.3 & $\chi^{2}=2.485$ \\
\hline - No & 12 & 41.4 & 18 & 62.1 & 30 & 51.7 & $\ddot{\mathbf{P}}=0.114$ \\
\hline
\end{tabular}


Table (2): Distribution of students according to their empathy total scores pre and post intervention

\begin{tabular}{|c|c|c|c|c|c|c|c|c|c|c|}
\hline \multirow{4}{*}{$\begin{array}{l}\text { Level of } \\
\text { Empathy }\end{array}$} & \multirow{2}{*}{\multicolumn{4}{|c|}{$\begin{array}{c}\text { Study } \\
\mathbf{n}=29\end{array}$}} & \multicolumn{4}{|c|}{$\begin{array}{c}\text { Control } \\
\mathbf{n}=29\end{array}$} & \multicolumn{2}{|c|}{$\begin{array}{c}\text { Test of significance } \\
\text { Between study and control } \\
\text { group }\end{array}$} \\
\hline & & & & & & & & & $\begin{array}{c}\text { Pre } \\
\text { intervention }\end{array}$ & $\begin{array}{c}\text { Post } \\
\text { intervention }\end{array}$ \\
\hline & \multicolumn{2}{|c|}{ Pre } & \multicolumn{2}{|c|}{ Post } & \multicolumn{2}{|c|}{ Pre } & \multicolumn{2}{|c|}{ Post } & $\chi^{2}=3.389$ & $\chi^{2}=16.75$ \\
\hline & No & $\%$ & No & $\%$ & No & $\%$ & No & $\%$ & $\mathbf{P}=0.065$ & $\mathbf{P}=0.000^{*}$ \\
\hline Low & 0 & 0.0 & 0 & 0.0 & 0 & 0.0 & 0 & 0.0 & & \\
\hline Moderate & 25 & 86.2 & 0 & 0.0 & 19 & 65.5 & 16 & 55.2 & & \\
\hline \multirow[t]{2}{*}{ High } & 4 & 13.8 & 29 & 100 & 10 & 34.5 & 13 & 44.8 & & \\
\hline & \multicolumn{4}{|c|}{$\begin{array}{l}\chi^{2}=4.296 \\
\mathbf{P}=0.038^{*}\end{array}$} & \multicolumn{4}{|c|}{$\begin{array}{l}\chi^{2}=0.648 \\
\mathbf{P}=0.420\end{array}$} & & \\
\hline
\end{tabular}

$\chi^{2}=$ Chi square test $\quad *$ Statistically significant at 0.05

Table (3): Distribution of students according to their emotional intelligence totals scores pre and post intervention

\begin{tabular}{|c|c|c|c|c|c|c|c|c|c|c|}
\hline \multirow{4}{*}{$\begin{array}{l}\text { Degree of } \\
\text { Emotional } \\
\text { Intelligence }\end{array}$} & \multirow{2}{*}{\multicolumn{4}{|c|}{$\begin{array}{c}\text { Study } \\
\mathrm{n}=29\end{array}$}} & \multirow{2}{*}{\multicolumn{4}{|c|}{$\begin{array}{c}\text { Control } \\
n=29\end{array}$}} & \multicolumn{2}{|c|}{$\begin{array}{c}\text { Test of significance } \\
\text { Between study and control } \\
\text { group }\end{array}$} \\
\hline & & & & & & & & & $\begin{array}{c}\text { Pre } \\
\text { intervention }\end{array}$ & $\begin{array}{c}\text { post } \\
\text { intervention }\end{array}$ \\
\hline & \multicolumn{2}{|c|}{ Pre } & \multicolumn{2}{|c|}{ Post } & \multicolumn{2}{|c|}{ Pre } & \multicolumn{2}{|c|}{ Post } & \multirow{5}{*}{$\begin{array}{c}\chi^{2}==1.14 \\
\mathrm{P}=0.428\end{array}$} & \multirow{5}{*}{$\begin{array}{l}\chi^{2}==1.69 \\
P=0.354\end{array}$} \\
\hline & No & $\%$ & No & $\%$ & No & $\%$ & No & $\%$ & & \\
\hline Low & 19 & 65.5 & 1 & 3.4 & 15 & 51.7 & 4 & 13.8 & & \\
\hline High & 10 & 34.5 & 28 & 96.6 & 14 & 48.3 & 25 & 86.2 & & \\
\hline $\begin{array}{l}\text { Test of } \\
\text { significance }\end{array}$ & \multicolumn{4}{|c|}{$\chi^{2}=24.72 \mathrm{P}=0.000^{*}$} & \multicolumn{4}{|c|}{$\chi^{2}=9.47 \quad \mathrm{P}=0.002 *$} & & \\
\hline
\end{tabular}

$\chi 2=$ Chi square test $\quad *$ Statistically significant at 0.05 
Table (4): Distribution of students according to their emotional intelligence subscales total scores pre and post intervention

\begin{tabular}{|c|c|c|c|c|c|c|c|c|c|c|}
\hline \multirow{3}{*}{$\begin{array}{l}\text { Emotional } \\
\text { intelligence } \\
\text { subscales }\end{array}$} & \multicolumn{4}{|c|}{$\begin{array}{c}\text { Study } \\
n=29\end{array}$} & \multicolumn{4}{|c|}{$\begin{array}{c}\text { Control } \\
n=29\end{array}$} & \multicolumn{2}{|c|}{$\begin{array}{c}\text { Test of significance } \\
\text { Between study and control } \\
\text { group }\end{array}$} \\
\hline & \multicolumn{2}{|c|}{ Pre } & \multicolumn{2}{|c|}{ Post } & \multicolumn{2}{|c|}{ Pre } & \multicolumn{2}{|c|}{ Post } & \multirow{2}{*}{$\begin{array}{c}\text { Pre } \\
\text { intervention }\end{array}$} & \multirow{2}{*}{$\begin{array}{c}\text { Post } \\
\text { intervention }\end{array}$} \\
\hline & No & $\%$ & No & $\%$ & No & $\%$ & No & $\%$ & & \\
\hline \multicolumn{11}{|c|}{ Appraisal of others emotions } \\
\hline Low & 24 & 82.7 & 14 & 48.3 & 21 & 72.4 & 20 & 69.0 & \multirow{3}{*}{$\begin{array}{l}\chi^{2}=0.89 \\
\mathrm{P}=0.532\end{array}$} & \multirow{3}{*}{$\begin{array}{l}\chi^{2}=2.55 \\
\mathrm{P}=0.181\end{array}$} \\
\hline High & 5 & 17.2 & 15 & 51.7 & 8 & 27.6 & 9 & 31.0 & & \\
\hline $\begin{array}{l}\text { Test of } \\
\text { significance }\end{array}$ & \multicolumn{4}{|c|}{$\begin{array}{l}\chi^{2}=0.892 \\
P=0.344\end{array}$} & \multicolumn{4}{|c|}{$\begin{array}{l}\chi^{2}=0.83 \\
P=0.772\end{array}$} & & \\
\hline \multicolumn{11}{|c|}{ Appraisal of own emotions } \\
\hline Low & 19 & 51.7 & 1 & 3.4 & 11 & 37.9 & 10 & 34.5 & \multirow{3}{*}{$\begin{array}{l}\chi^{2}=2.38 \\
\mathrm{P}=0.138\end{array}$} & \multirow{3}{*}{$\begin{array}{c}\chi^{2}=0.531 \\
P=0.553 \\
p: 0.0001\end{array}$} \\
\hline High & 14 & 48.3 & 28 & 96.6 & 18 & 62.1 & 19 & 65.5 & & \\
\hline $\begin{array}{l}\text { Test of } \\
\text { significance }\end{array}$ & \multicolumn{4}{|c|}{$\begin{array}{c}\chi=20.69 \\
P=0.000 *\end{array}$} & \multicolumn{4}{|c|}{$\begin{array}{l}\chi^{2}=0.351 \\
\mathbf{P}=0.553\end{array}$} & & \\
\hline \multicolumn{11}{|c|}{ Regulations of emotions } \\
\hline Low & 17 & 58.6 & 1 & 3.4 & 15 & 51.7 & 12 & 27.6 & \multirow{3}{*}{$\begin{array}{l}\chi^{2}=0.278 \\
P=0.597\end{array}$} & \multirow{3}{*}{$\begin{array}{c}\chi^{2}=6.44 \\
\mathrm{P}=0.023^{*}\end{array}$} \\
\hline High & 12 & 41.4 & 28 & 96.6 & 14 & 48.3 & 17 & 72.4 & & \\
\hline $\begin{array}{l}\text { Test of } \\
\text { significance }\end{array}$ & \multicolumn{4}{|c|}{$\begin{array}{l}\chi^{2}=20.62 \\
P=0.000 *\end{array}$} & \multicolumn{4}{|c|}{$\begin{aligned} \chi^{2} & =0.623 \\
P & =0.429\end{aligned}$} & & \\
\hline \multicolumn{11}{|c|}{ Social skills } \\
\hline Low & 16 & 55.1 & 2 & 6.9 & 16 & 55.2 & 8 & 27.6 & \multirow{3}{*}{$\begin{array}{l}\chi^{2}=0.0 \\
P=0.1\end{array}$} & \multirow{3}{*}{$\begin{array}{l}\chi^{2}=4.35 \\
\mathrm{P}=0.077\end{array}$} \\
\hline High & 13 & 44.8 & 27 & 93.1 & 13 & 44.8 & 21 & 72.4 & & \\
\hline $\begin{array}{l}\text { Test of } \\
\text { significance }\end{array}$ & \multicolumn{4}{|c|}{$\begin{array}{l}\chi^{2}=15.79 \\
P=0.000 *\end{array}$} & \multicolumn{4}{|c|}{$\begin{array}{l}\chi^{2}=4.549 \\
P=0.033^{*}\end{array}$} & & \\
\hline & & & & Uti & zatio & of em & ions & & & \\
\hline Low & 19 & 65.5 & 1 & 3.4 & 13 & 44.8 & 10 & 34.5 & $\chi^{2}=2.51$ & $\chi^{2}=9.087$ \\
\hline High & 10 & 34.5 & 28 & 96.6 & 16 & 55.2 & 19 & 65.5 & $\mathrm{P}=0.194$ & $\mathrm{P}=0.002 *$ \\
\hline $\begin{array}{l}\text { Test of } \\
\text { significance }\end{array}$ & & $\begin{array}{l}\chi^{2}=2 \\
\mathbf{P}=\mathbf{0} .\end{array}$ & 0.72 & & & $\begin{array}{l}\chi^{2}= \\
\mathbf{P}=1\end{array}$ & $\begin{array}{l}648 \\
21 \\
\end{array}$ & & & \\
\hline & & & & & Op & mism & & & & \\
\hline Low & 18 & 62.1 & 16 & 55.2 & 19 & 65.5 & 17 & 58.6 & $\chi^{2}=1.73$ & $\chi^{2}=0.703$ \\
\hline High & 11 & 37.9 & 13 & 44.8 & 10 & 34.5 & 12 & 41.4 & $\mathrm{P}=0.29$ & $\mathrm{P}=0.790$ \\
\hline $\begin{array}{l}\text { Test of } \\
\text { significance }\end{array}$ & & $\begin{array}{l}\chi^{2}=2 \\
\mathbf{P}=0\end{array}$ & $\begin{array}{l}843 \\
593\end{array}$ & & & $\begin{array}{l}\chi^{2}= \\
\mathbf{P}=1\end{array}$ & $\begin{array}{l}292 \\
87\end{array}$ & & & \\
\hline
\end{tabular}


Table (5): Mean scores for students' empathy scores before and after intervention for both study and control groups

\begin{tabular}{|c|c|c|c|c|c|c|c|}
\hline \multicolumn{3}{|c|}{ Study $(n=29)$} & \multicolumn{3}{|c|}{ Control $(n=29)$} & \multicolumn{2}{|c|}{$\begin{array}{c}\text { Test of significance } \\
\text { Between study and control } \\
\text { group }\end{array}$} \\
\hline Before & After & $\begin{array}{l}\text { Mean } \\
\text { change }\end{array}$ & Before & After & $\begin{array}{l}\text { Mean } \\
\text { change }\end{array}$ & $\begin{array}{c}\text { Pre } \\
\text { intervention }\end{array}$ & $\begin{array}{c}\text { post } \\
\text { intervention }\end{array}$ \\
\hline $\mathbf{M} \pm \mathbf{S D}$ & $\mathbf{M} \pm \mathbf{S D}$ & $\mathrm{M} \pm \mathrm{SD}$ & $\mathrm{M} \pm \mathrm{SD}$ & $\mathrm{M} \pm \mathrm{SD}$ & $\mathbf{M} \pm \mathrm{SD}$ & $F^{a}=-1.71$ & $F^{b}=3.618$ \\
\hline $\begin{array}{l}67.97 \pm \\
4.99\end{array}$ & $\begin{array}{l}71.45 \pm \\
6.85\end{array}$ & $\begin{array}{l}3.48 \pm \\
1.86\end{array}$ & $\begin{array}{l}77.45 \pm \\
14.76\end{array}$ & $\begin{array}{l}78.59 \pm \\
15.25\end{array}$ & $\begin{array}{c}1.14 \pm \\
0.49\end{array}$ & $\mathrm{P}=0.097$ & $\mathrm{P}=0.001 *$ \\
\hline \multicolumn{3}{|c|}{$\begin{array}{c}\text { Paired } \mathrm{t} \text { test } \\
\mathrm{t}=2.966 \quad \mathrm{P}=0.006^{*}\end{array}$} & \multicolumn{3}{|c|}{$\begin{array}{c}\text { Paired } \mathrm{t} \text { test } \\
\mathrm{t}=-0.689 \quad \mathrm{P}=0.497\end{array}$} & & \\
\hline
\end{tabular}

F: ANOVA test $\quad$ *Statistically significant at 0.05

Table (6): Mean scores for the emotional intelligence scores before and after intervention for both study and control groups

\begin{tabular}{|c|c|c|c|c|c|c|c|}
\hline \multicolumn{3}{|c|}{ Study $(n=29)$} & \multicolumn{3}{|c|}{ Control(n=29) } & \multirow{2}{*}{\multicolumn{2}{|c|}{$\begin{array}{c}\text { Test of significance } \\
\text { Between study and control } \\
\text { group }\end{array}$}} \\
\hline Before & After & Mean & Before & After & Mean & & \\
\hline $\mathrm{M} \pm \mathrm{SD}$ & $\mathrm{M} \pm \mathrm{SD}$ & $\mathrm{M} \pm \mathrm{SD}$ & $\mathrm{M} \pm \mathrm{SD}$ & $\mathrm{M} \pm \mathrm{SD}$ & $\mathrm{M} \pm \mathrm{SD}$ & $\begin{array}{c}\text { Pre } \\
\text { intervention }\end{array}$ & $\begin{array}{c}\text { post } \\
\text { intervention }\end{array}$ \\
\hline $\begin{array}{c}119.28 \pm \\
12.6\end{array}$ & $\begin{array}{c}135.07 \pm \\
6.52 \\
\end{array}$ & $\begin{array}{c}15.79 \pm \\
6.08\end{array}$ & $\begin{array}{c}120.10 \pm \\
7.58 \\
\end{array}$ & $\begin{array}{c}133.79 \pm \\
10.73\end{array}$ & $\begin{array}{c}13.69 \pm \\
3.15\end{array}$ & $\begin{array}{c}\mathrm{F}=1.662 \\
\mathrm{P}=1.849\end{array}$ & $\begin{array}{l}F=1.641 \\
P=0.193\end{array}$ \\
\hline \multicolumn{3}{|c|}{ Paired t test } & \multicolumn{2}{|c|}{ Paired t test } & $0 *$ & & \\
\hline
\end{tabular}

F: ANOVA test $\quad *$ Statistically significant at 0.05 


\section{References}

1. Applebaum, D., Fowler, S., Fiedler, N., Osinubi, O. and Robson, M. The impact of environmental factors on nursing stress, job satisfaction, and turnover intention. The Journal of Nursing Administration 2010; 40, (7/8):323-8.

2. Ranasinghe, P., Wathurapatha, W.S., Mathangasinghe, Y. and Ponnamperuma, G. Emotional intelligence, perceived stress and academic performance of Sri Lankan medical undergraduates. BMC Medical Education 2017; 17(1): 41.

3. Nasir, M. and Masrur, R. An exploration of emotional intelligence of the students of IIUI in relation to gender, age and academic achievement. Bulletin of Education and Research 2010; 32 (1).

4. Fujino, Y., Tanaka, M., Yonemitsu, Y. and Kawamoto, R. The relationship between characteristics of nursing performance and years of experience in nurses with high emotional intelligence. International Journal of Nursing Practice 2015; 21(6): 876-81.

5. Esmaeili, R., AlizadehNavaei, R., Godarzian, A.H. and Yousefi, M. The effect of emotional intelligence training on the quality of working life in nurses. Journal of Health Science 2015; 3 : 241-7.

6. Harper, M.G. and Jones-Schenk, J. The emotional intelligence profile of successful staff nurses.The Journal of Continuing Education in Nursing 2012; 43(8): 354-62.

7. Lyon, S., Trotter, F., Holt, B., Powell, E. and Roe, A. Emotional intelligence and its role in recruitment of nursing students. Journal of Nursing Standard 2013; 27(40): 41-6.
8. Por, J., Barriball, L., Fitzpatrick, J. and Roberts, J. Emotional intelligence: Its relationship to stress, coping, well-being and professional performance in nursing students. Journal of Nurse Education Today 2011; 31(8): 855-60.

9. Salovey P, Mayer JD. Emotional intelligence. Imagin Cogn Pers; 9: 185211. doi: 10.2190/DUGG-P24E-52WK6CDG, 1990. In Wijekoon, C.N., Amaratunge, H., de Silva, Y., Senanayake, S., Jayawardane, P. and Senarath, U. Emotional intelligence and academic performance of medical undergraduates: a cross-sectional study in a selected university in Sri Lanka. BMC Medical Education 2017; 17(1): 176.

10. Benson, G., Ploeg, J. and Brown, B. A cross-sectional study of emotional intelligence in baccalaureate nursing students. Journal of Nurse Education Today 2010; 30(1): 49-53.

11. Ugoani, J. and Amu, C. Dimensions of emotional intelligence and transformational leadership: A correlation analysis. Independent Journal of Management \& Production (IJM\&P) 2015; 6 (2): 2236-269X

12. Scudder, L. The loss of empathy in nursing education. Medscape Multispecialty/ News \& Perspective/ Medscape Nurses/ Viewpoints. 2012, March 12. Retrieved from www.medscape.com/viewarticle/759695.

13. Maruca, A.T., Díaz, D.A., Kuhnly, J.E. and Jeffries, P.R. Enhancing empathy in undergraduate nursing students: An experiential ostomate simulation. Journal of nursing education perspectives 2015; 36(6): 367-71.

14. Ogle J, Bushnell JA, Caputi P 2013 Empathy is related to clinical competence in medical care.Med Educ. Aug; 47(8):824-31. 
15. Umphrey, R.H. The benefits of emotional intelligence and empathy to entrepreneurship. Entrepreneurship Research Journal 2013; 3(3): 287-94.

16. Okkinos, C.M. and Kipritsi, E. The relationship between bullying, victimization, trait emotional intelligence, self-efficacy and empathy among preadolescents. Social psychology of education 2012; 15(1): 41-58.

17. Goleman, D., Boyatzis, R.E. and McKee, A. Primal leadership: Unleashing the power of emotional intelligence. Harvard Business Press, 2013.

18. Kinman, G. and Leggetter, S. November. Emotional labour and wellbeing: what protects nurses?. In Health care Multidisciplinary Digital Publishing Institute 2016; 4(4): 89).

19. Johnson, S.J., Machowski, S., Holdsworth, L., Kern, M. and Zapf, D. Age, emotion regulation strategies, burnout, and engagement in the service sector: Advantages of older workers. Revista de Psicologíadel Trabajo y de las Organizaciones 2017; 33(3): 205-16.

20. Lamothe, M., Rondeau, É., MalboeufHurtubise, C., Duval, M. and Sultan, S. Outcomes of MBSR or MBSR-based interventions in health care providers: A systematic review with a focus on empathy and emotional competencies. Complementary Therapies in Medicine 2016; 24:19-28.

21. Grant, L. and Kinman, G. Emotional resilience in the helping professions and how it can be enhanced. Health and Social Care Education 2014; 3 (1): 23-34.

22. Nightingale, S., Spiby, H., Sheen, K. and Slade, P. The impact of emotional intelligence in health care professionals on caring behavior towards patients in clinical and long-term care settings: Findings from an integrative review. International journal of nursing studies 2018; 80 (6): 106-17

23. Konstantinou, M.S., Efstathiou, A., Charalambous, G., Kaitelidou, D. and Jelastopulu, E. Emotional intelligence and its impact on the emotional factors among nurses. Journal of Education Society and Behavioural Science 2017; 23(3): 1-13.

24. Reemts, G.S. Emotional intelligence levels in baccalaureate-prepared early career registered nurses. Asia-Pacific Journal of Oncology Nursing 2015; 2 (2): 72.

25. Khademalhosseini M, Khademalhosseini Z, Mahmoodian F. Comparison of empathy score among medical students in both basic and clinical levels. Journal of Advances in Medical Education and Professionalism 2014; 2: 88-91.

26. Hojat M, Gonella JS, Nasca TJ, Mangione $S$, Vergare $M$, Magee M. Physician empathy: Definition, components, measurement, and relationship to gender and specialty. American Journal of Psychiatry 2002; 159:1563-9.

27. Fields SK, Mahan P, Tillman P, Harris J, Maxwell K, Hojat M. Measuring empathy in healthcare profession students using the Jefferson Scale of Physician Empathy: health provider-student version. Journal of. Interprofessional Care 2011; 25: $287-$ 93.

28. Schutte, N. S., Malouff, J. M., Hall, L. E., Haggerty, D. J., Cooper, J. T., Golden, C.J., and Dornheim, L. Development and validity of a measure of emotional intelligence. Personality and Individual Differences 1998; 25: 167-77.

29. Kamel NMF. Alexthymia and empathy, how to understand our emotions? emotional awareness \& emotional understanding, ISBN-10: 3659499943: LAP LAMBERT Academic Publishing, 2014. 
30. Aktas S, Pasinlioglu T, Calik KY. The effect of empathy training given to midwives on mothers' satisfaction with midwives and their birth perception. International Journal of Nursing and Health Sciences 2016; 3(9):110-17.

31. Kahriman I, Nural N, Arslan U, Topbas M, Can G, Kasim S. The effect of empathy training on the empathic skills of nurses. Iranian Red Crescent Medical Journal 2016; 18(6):1-10

32. Cunico L, Sartori R, Marognolli O, Meneghini AM. Developing empathy in nursing students: a cohort longitudinal study. Journal of Clinical Nursing 2012; 21(13-14): 25.

33. Ozcan CT, Oflaz F, Bakir B. The effect of a structured empathy courses on the students of a medical and a nursing school. International Nursing Review 2012; 59(4): 532-8.

34. Akbari, M., Pouretemad, H.R., SalehSedghpour, B. The effect of an assertiveness, problem solving and selfregard intervention-training program on emotional intelligence. J. Appl. Psychol. 2010; 4 (13): 52-64.

35. Beauvais, A.M., Brady, N., O'shea, E.R., Quinn Griffin, M.T. Emotional intelligence and nursing performance among nursing students. Nurse Education Today 2011; 31: 396-401.

36. Orak RJ, Farahani MA, Kelishami FG, Seyedfatemi N, Banihashemi S, Havaei F. Investigating the effect of emotional intelligence education on baccalaureate nursing students' emotional intelligence scores. Nurse Education and Practice 2016; 20: 64-69. doi: 10.1016/j.nepr.2016.05.007. Epub 2016 Jun 23.

37. Keiko A, Masayuki N, Kazuhiko $\mathrm{F}$ and Yasuyuki S. Associations between emotional intelligence, empathy and personality in Japanese medical students BMC Medical Education 2018; 18 (1): 47.

38. Saeed Abbasi, Tayebeh Rakhshani, Mahdi Rezaie, Mohammad Reza Ebrahimi, Samira Taravatmanesh. A study of emotional intelligence and the effect of educational intervention in emergency medicine residents. Archives of Psychiatry and Psychotherapy 2018; 1: 45-52.

39. Keshavarz N, Amini M, Mani A. A study on the relationship between emotional intelligence and academic achievement in students of Shiraz University of Medical Sciences. Interdisciplinary Journal of Virtual Learning in Medical Sciences 2014; 5 (3): 70-7.

40. Gorgas DL, Greenberger S, Bahner DP. Teaching emotional intelligence: a control group study of a brief educational intervention for emergency medicine residents. Western Journal of Emergence Medicine 2015; 16(6): 899-906.

41. Stoller JK, Taylor CA, Farver CF. Emotional intelligence competencies provide a developmental curriculum for medical training. Medical Teacher 2013; 35(3): 243-7. 